\title{
A new approach to kimberlite facies terminology using a revised general approach to the nomenclature of all volcanic rocks and deposits: descriptive to genetic.
}

\author{
Ray Cas ${ }^{1}$, Lucy Porritt ${ }^{1}$, Adrian Pittari ${ }^{1}$ and Pat Hayman ${ }^{1}$ \\ ${ }^{1}$ School of Geosciences, Monash University, Clayton, Victoria, Australia, 3800.
}

\section{Introduction}

Although kimberlite pipes/bodies are usually the remains of volcanic vents, in-vent deposits, and subvolcanic intrusions, the terminology used for kimberlite rocks has largely developed independently of that used in mainstream volcanology. Existing kimberlite terminology is not descriptive and includes terms that are rarely used, used differently, and even not used at all in mainstream volcanology. In addition, kimberlite bodies are altered to varying degrees, making application of genetic terminology difficult because original components and depositional textures are commonly masked by alteration. This paper recommends an approach for developing terminology for kimberlite rocks that is consistent with usage for other volcanic successions, and follows the approach of Cas et al. (2008).

In modern terrains the eruption and emplacement origins of deposits can often be readily deduced, but this is often not the case for old, variably altered and deformed rock successions. A staged approach is required whereby descriptive terminology is developed first, followed by application of genetic terminology once all features, including the effects of alteration on original texture and depositional features, together with contact relationships and setting, have been evaluated. Because many volcanic successions consist of both primary volcanic deposits as well as volcanic sediments, terminology must account for both possibilities.

\section{Approach to classification}

Cas et al. (2008) have proposed a systematic approach to the documentation of the depositional facies characteristics of the deposits of kimberlite bodies, including components, textural features and depositional structures. This initial descriptive approach allows descriptive facies names to be applied, which can then be developed into genetic terms. Development of terms requires distinct stages of observation and interpretatiion as follows:

1. In the first instance, the components and groundmass features of coherent kimberlite versus matrix features of fragmental kimberlite need to be documented (Table 1). Different approaches are required for coherent and fragmental kimberlites because they each have distinctive textural features. Coherent kimberlite can be emplaced as subsurface crustal intrusions (= hypabyssal setting), in-vent intrusions and even as

Table 1. Components and textural elements of coherent and fragmental kimberlite (from Cas et al. 2008, Table 1)

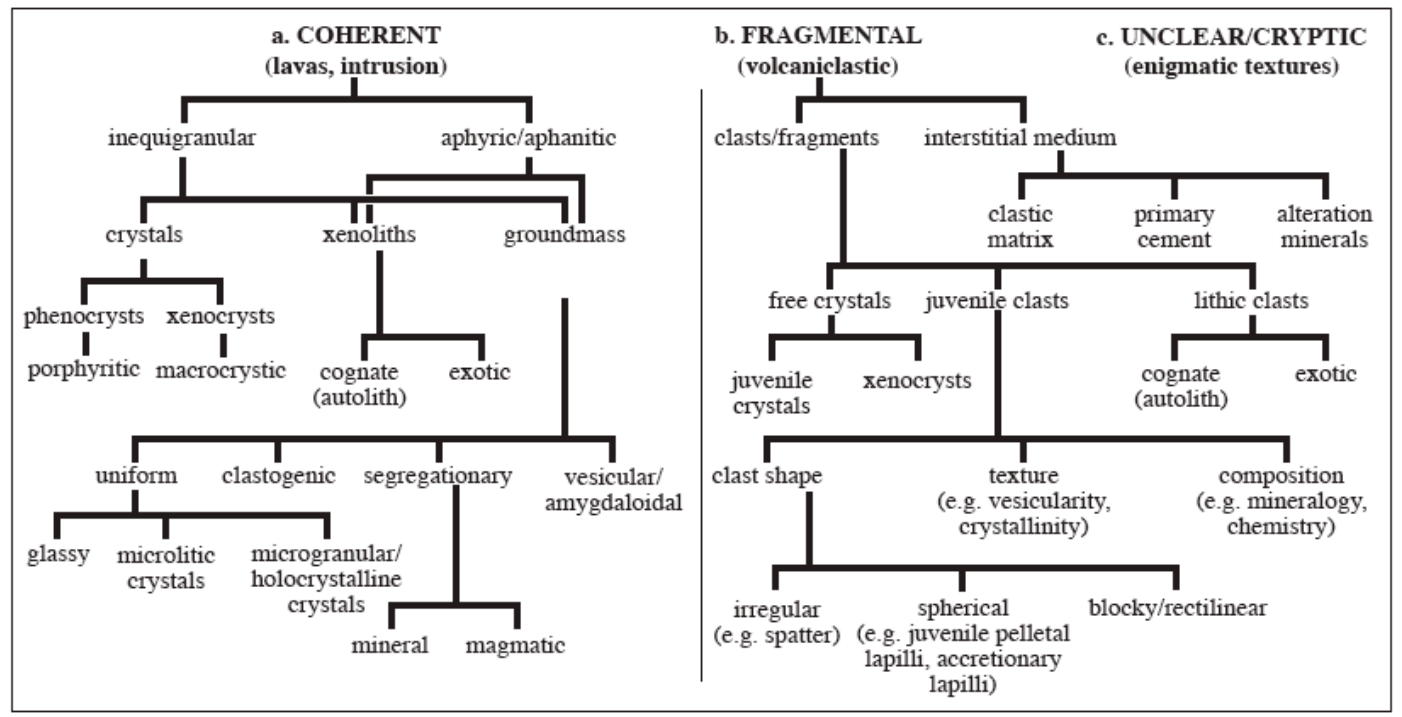


lavas, and all three can be texturally similar. the term coherent is preferred to hypabyssal, To avoid confusion between level of emplacement and textural character, the term coherent is preferred to hypabyssal . 2. The size of crystals in coherent rocks and the size of clasts in fragmental rocks are described using recommended size classification tables and descriptive size terms (Table 2).

Table 2. a. Crystal size terms, and b. fragment size terms for coherent and fragmental kimberlite (from Cas et al. 2008, Table 2).

\begin{tabular}{|c|c|c|c|}
\hline \multicolumn{2}{|l|}{ a } & \multicolumn{2}{|l|}{ b } \\
\hline$\varangle 0.0625 \mathrm{~mm}$ & microlites, microcrystals & $<0.0625 \mathrm{~mm}$ & clay/silt size fragmental deposit/rock \\
\hline $0.0625-0.25 \mathrm{~mm}$ & fine crystals & $0.0625-0.125 \mathrm{~mm}$ & 1 very fine sand size fragmental deposit/rock \\
\hline $0.25-0.5 \mathrm{~mm}$ & medium crystals & $0.125-0.25 \mathrm{~mm}$ & fine sand size fragmental deposit/rock \\
\hline $0.5-1 \mathrm{~mm}$ & coarse crystals & $0.25-0.5 \mathrm{~mm}$ & medium sand size fragmental deposit/rock \\
\hline $1-2 \mathrm{~mm}$ & very coarse crystals & $0.5-1 \mathrm{~mm}$ & coarse sand size fragmental deposit/rock \\
\hline $2-4 \mathrm{~mm}$ & extremely coarse crystals & $1-2 \mathrm{~mm}$ & very coarse sand size fragmental deposit/rock \\
\hline $4-8 \mathrm{~mm}$ & large crystals & $2-4 \mathrm{~mm}$ & grit/granule size fragmental deposit/rock \\
\hline $8-16 \mathrm{~mm}$ & very large crystals & $4-8 \mathrm{~mm}$ & very fine pebble size fragmental deposit/rock \\
\hline $16-32 \mathrm{~mm}$ & extremely large crystals & $8-16 \mathrm{~mm}$ & fine pebble size fragmental deposit/rock \\
\hline$>32 \mathrm{~mm}$ & extraordinarily large crystals & $16-32 \mathrm{~mm}$ & medium pebble size fragmental deposit/rock \\
\hline & (e.g. spinifex, pegmatite & $32-64 \mathrm{~mm}$ & coarse pebble size fragmental deposit/rock \\
\hline & crystals) & $\begin{array}{l}64-256 \mathrm{~mm} \\
>256 \mathrm{~mm}\end{array}$ & $\begin{array}{l}\text { cobble size fragmental deposit/rock } \\
\text { boulder size fragmental deposit/rock }\end{array}$ \\
\hline
\end{tabular}

3. Levels of sorting in fragmental rocks are described using standard sorting classes applied in sedimentology. Using sorting textural class names applied to clastic carbonates (mudstone $=$ all clay-silt size particles; wackestone $=$ mudstone with dispersed framework grains; packstone = grain-supported framework with mud-size matrix; grainstone = grainsupported framework without mud-matrix) provides insights into physical eruption and depositional processes and their sorting efficiencies (Table 3 ).

Table 3: sorting classes and textural sorting class names (from Cas et al. 2008, Table 3).

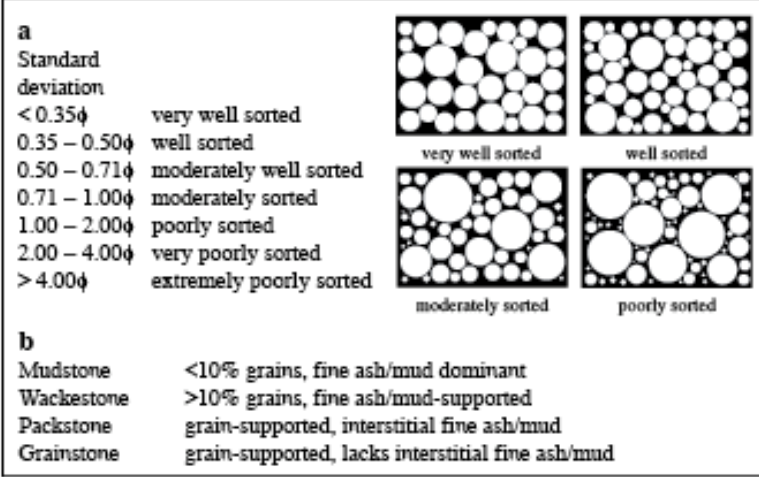

4. Assessment of crystal shapes and particle rounding are considered next.

5. Assess the crystal abundance using the ranges listed in Table 4.

6. Assess the abundance of vesicles. Use the same abundance terms for coherent kimberlite and clasts in fragmental kimberlite (Table 5).

7. Combine components, and various textural fetures to produce a descriptive petrological term (e.g. serpentine altered, moderately macrocrystic, coarse, non-vesicular, monticellite kimberlite; serpentinecarbonate altered, poorly sorted, moderately crystal rich, olivine-uncored pelletal lapilli, grain supported, coarse sand-size packstone)

Table 4. Crystal abundance classes (from Cas et al. 2008, Table 5).

\begin{tabular}{|ll|}
\hline & \\
$<\%$ & aphyric/crystal free \\
$<10 \%$ & crystal-poor \\
$10-25 \%$ & moderately crystal-rich \\
$25-50 \%$ & crystal-rich \\
$50-80 \%$ & very crystal-rich \\
$>80 \%$ & extremely crystal-rich \\
\hline
\end{tabular}

Table 5. Vesicle abundance classes (from Cas et al. 2008, Table 6; after Houghton and Wilson 1989).

\begin{tabular}{|ll|}
\hline & \\
$0 \%$ & non-vesicular \\
$0-20 \%$ & very poorly vesicular \\
$20-40 \%$ & poorly vesicular \\
$40-60 \%$ & moderately vesicular \\
$60-80 \%$ & very vesicular \\
$>80 \%$ & extremely vesicular (reticulite) \\
\hline
\end{tabular}

8. Describe the principal emplacement/depositional structures and unit thickness.

9. Describe the contact relationships between units (conformable, intrusive, faulted).

10. Apply appropriate genetic size terminology to fragmental deposits after deciding if the origin is pyroclastic, autobrecciation, quench fragmentation, hydraulic fracturing or sedimentary epiclastic (Table $6)$.

11. Interpret the emplacement setting (extra-vent; intravent) and emplacement/depositional process (Table 7). 
12. Apply a genetic term, if possible, that combines key descriptive facies features with emplacement origins and setting (e.g. crater zone, thin, tabular, moderately crystal-rich, macrocrystic, non-vesicular, olivine-phlogopite, orangeite dyke; intra-vent, massive, olivine rich, lapilli-tuff, column collapse deposit; diatreme zone, well-sorted, diffusely bedded, olivine sandstone turbidite; extra-vent, thinly bedded, wellsorted, crystal-rich, olivine, very coarse tuff, fallout deposit).

Table 6. Genetic terminology for different types of fragmental kimberlite based on fragmentation style and grainsize (from Cas et al. 2008, Table 10).

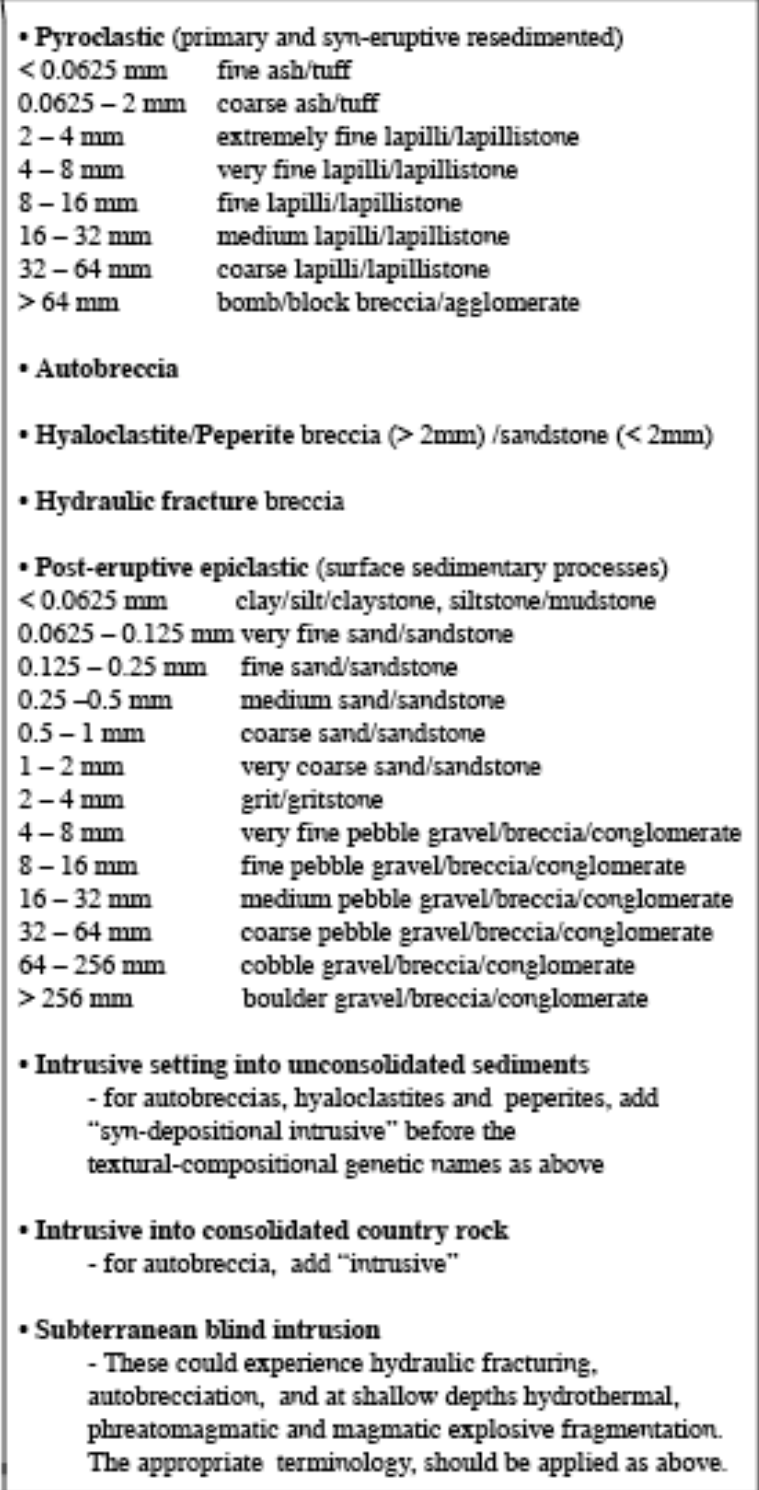

Table 7. Emplacement setting and origin for a. coherent and b. fragmental kimberlite (from Cas et al. 2008, Table 11).

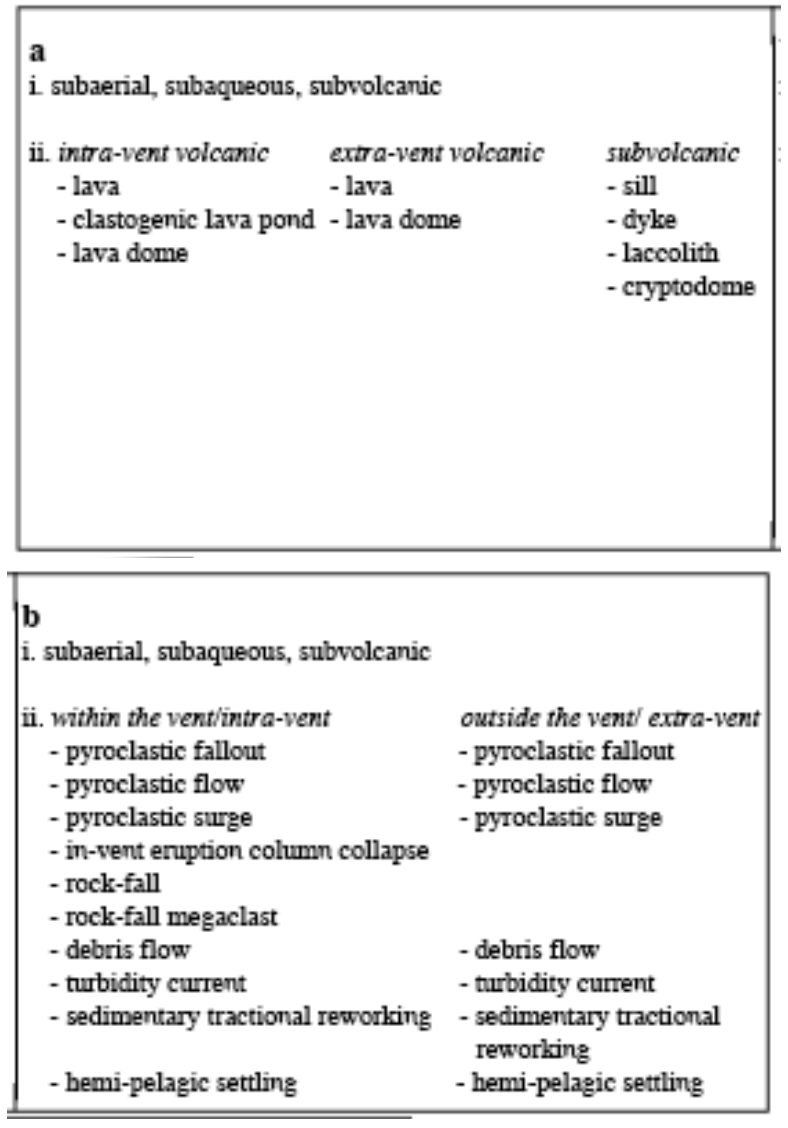

\section{References}

Cas, R.A.F., Porritt, L., Pittari, A., Hayman, P. 2008. A new approach to kimberlite facies terminology using a revised general approach to nomenclature for all volcanic rocks: descriptive to genetic. Journal of Volcanology and Geothermal Research, 174, 226240.

Houghton, B. and Wilson, C.J.N. 1989. A vesicularity index for pyroclastic deposits: Bulletin of Volcanology, $51,451-462$. 